\title{
Deleuze e a forma imutável da diferenciação
}

\author{
GABRIEL PRADO RODRIGUES *
}

\begin{abstract}
RESUMO O objetivo deste trabalho é a apresentação e a articulação do conceito de forma imutável da mudança ou forma pura e vazia do tempo segundo o modo em que aparece no sistema filosófico de Gilles Deleuze. Passando pela elucidação do conceito no contexto kantiano em que é sistematizado pela primeira vez, tentamos elucidar o pano de fundo ontológico temporal em que a noção é apropriada por Deleuze, a partir de um movimento duplo de crítica e reabilitação do kantismo. É então explanada a relação da forma do tempo com a noção de terceira síntese do tempo, a partir da qual a forma ganha uma função destrutiva e geneticamente diferencial. Por fim, tentamos mostrar e desenvolver como essa propriedade diferencial redunda em uma ontologia caracterizada pela necessidade e estrita universalidade de sua plasticidade destrutiva, signo de relação imanente com uma potência caótica ou absolutamente criativa.
\end{abstract}

PALAVRAS-chaVe Deleuze; diferença; forma; tempo.

\section{DELEUZE, KANT E O TEMPO COMO DIMENSÃO DETERMINÁVEL}

Em Deleuze, a noção de criatividade importa muito pouco sem a demarcação das condições sob as quais o novo pode ser produzido. Toda criação desdobra-se a partir de um movimento de deformação sistemática, de aberração imanente manifesto em três aspectos correlacionados. Primeiro, no de que toda criação se dá progressivamente, sem determinação possível de seu início e seu fim; segundo, de que a essência dessa progressão é a reformulação gradativa de campos sistemáticos estruturados

* PUC-Rio

Mestrando do Programa de Pós-Graduação em Filosofia

Bolsista do CNPQ 
e, portanto, destruição criadora ou criação destrutiva ${ }^{1}$. Terceiro, de que os sistemas reformulados são facetas secundárias, estruturadas, atualizadas de um movimento de diferenciação que, em seu curso independente, é responsável por todo movimento possível ocorrido no âmbito do sistema organizado, da estrutura ${ }^{2}$. Este, por sua vez, possui, em relação ao movimento de diferenciação, o estatuto de um efeito, de uma afecção ${ }^{3}$. A criação é, portanto, sempre uma aberração: dada a singularidade de seu produto, lhe faltam, de início, meios de expressão suficientemente determinados, o que a torna dependente de uma instanciação preliminar em estruturações já estabelecidas até que encontre, nessas mesmas estruturações, uma abertura que permita sua deformação criativa.

De um ponto de vista filosófico, criar consiste em seguir a lógica de um arranjo conceitual até o ponto em que sua coerência, encarnada no encadeamento entre elementos produtor de sua unidade de sentido, é rachada, dando lugar à emergência intensiva de um novo sistema, produzido a partir dos estilhaços do primeiro. A criação demanda, assim, uma efetiva imersão no pensamento de cada autor, em cada campo de sentido mais ou menos delimitado, até o ponto que o conjunto como um todo é inscrito no engendramento de concepções que o ultrapassam. É nesse sentido que Deleuze é tanto estruturalista, spinozista e nietzschiano quanto fundador de sua posição singular, irredutível a essas categorizações. Ele não pode deixar de oscilar entre o endosso e a rejeição de certas linhagens teóricas; sobretudo, do estruturalismo, da psicanálise,

1 Cf. LAPOUJADE, Deleuze, os movimentos aberrantes, p.11: "É preciso extrair a intuição que 'faz o sistema cindir', como dizia Bergson, às vezes ao ponto do sistema voltar-se contra si mesmo, ao ponto em que Platão indica a direção de uma 'reversão do platonismo', ao ponto em que Kant descobre, na terceira Crítica, um uso desregrado de todas as faculdades".

2 Essa formulação não indica que o termo sistema seja sinônimo de organização completamente fechada, apenas que todo sistema se constitua na base de algum nível de organização que não seja puramente diferencial, que comporte, portanto, algum nível em que a diferença produza identidade. Um sistema compreende "ressonância” e um "movimento forçado", mas também "qualidades e extensos que se desenvolvem a partir desses dinamismos". (DELEUZE, Diferença e repetição, p.174)

3 “[...]a semelhança, a identidade, a analogia, a oposição só podem ser consideradas como efeitos, produtos de uma diferença primeira ou de um sistema primeiro de diferenças". (Diferença e repetição, p.171)

Na mesma linha, dirá Michael Hardt que Deleuze “não questiona como o ser pode ganhar determinação, como o ser pode sustentar sua diferença, mas, antes, como a diferença pode 'sustentar seu ser' [peut tenir son être]. Deleuze dá à diferença um papel radicalmente novo. A diferença funda o ser; fornece ao ser sua necessidade, sua substancialidade.” (HARDT, Gilles Deleuze: An Apprenticeship in Philosophy, p.5; tradução nossa) 
mas também, com mais ambiguidade, das posições de autores eleitos como intercessores por sua filosofia, tais como, manifestamente, Maimon, Nietzsche, Spinoza, Bergson, etc.

É no pano de fundo da ambiguidade das apropriações deleuzianas de outros autores que reside a possibilidade de afirmação de seu kantismo, sem que se ignore, simultaneamente, a caracterização de Kant como um inimigo, cuja filosofia do juízo deveria ser, antes de tudo, superada. Deleuze é kantiano na medida em que sua articulação da filosofia crítica compreende o objetivo último de sua superação criativa, o que é levado à cabo através da reativação do problema da gênese da experiência sobre novas bases conceituais. Isto posto, neste trabalho, passaremos, em primeiro lugar, à apresentação e à articulação do problema kantiano; e, em segundo lugar, à explanação do modo como, no interior da primeira Crítica, é contextualizado o conceito de forma estética transcendental do tempo, fundamental para o desenvolvimento da ontologia deleuziana.

A contribuição fundamental de Kant, para Deleuze, consiste na descoberta de uma rachadura ou fissura entre "a determinação e o que ela determina" ${ }^{\text {, }}$ entre o condicionamento transcendental e a experiência empírica. Essa cisão teria nascido não tanto da rejeição kantiana do empirismo, melhor encarnado no naturalismo humeano, mas na sua complementação na direção de uma nova concepção de necessidade, ignorada pelo empirismo dada sua limitação a um ponto de vista exclusivamente empírico. No fundo, é esta a objeção fundamental de Kant a Hume: não é que a realidade seja indeterminada (o que se seguiria caso se pretendesse, à maneira do empirismo ingênuo, derivar a determinação da empiria), é a determinação que escapa à experiência pois está lá desde o início, às suas costas. Ela é condição da experiência, evidenciada em sua regularidade, mas lhe escapa por ser a ela irredutível, estando posta, de antemão, como pura, a priori.

O caráter apriorístico do condicionamento da experiência encontrará na figura do sujeito sua fonte de legitimação. A filosofia crítica passará a definir-se pela posição de um condicionamento idealista como matriz da realidade empírica ou fenomênica. O mundo fenomênico, por sua vez, deve circunscrever o plano objetivo, em que 
objetos se relacionam causalmente segundo sua conformação a uma espacialidade discreta e a uma temporalidade cronológica. A constituição desse plano se dá por um processo de determinação, em que o sujeito ativamente aplica formas lógicas conceituais (as categorias), presentes a priori no próprio sujeito, sobre o chamado "múltipo" ou "diverso", recebido passivamente através da faculdade da intuição sensível. Esse processo, no entanto, não se dá sem o intermédio de um esquema, composto por propriedades formais da própria sensibilidade ou formas estéticas a priori, o espaço e o tempo. Não há ordenação do diverso sensível pelas categorias sem que o primeiro passe, antes, pelo crivo das formas estéticas, constituintes do próprio modo pelo qual aparecem os objetos fenomênicos: durando no tempo e ocupando o espaço. O múltiplo é, portanto, a matéria desorganizada para que as formas subjetivas fornecem uma modulação mediante a qual o diverso da intuição ganha, entre outras propriedades, as de simultaneidade e de sucessão, características dos objetos fenomênicos em ge$\mathrm{ral}^{5}$. Categorias e formas estéticas são, assim, ditas transcendentais por demarcarem as condições de qualquer configuração que qualquer objeto espaço-temporalmente instanciado possa vir a tomar.

Destarte, segundo a fórmula de Kant, seu "idealismo transcendental" é também um “realismo empírico" : ele preserva todas as características impressas pela física moderna à realidade com a ressalva de que essas características, são, no fundo, resultado de conformidade a estruturas subjetivas. Em lugar do caráter absoluto de que são dotados na física newtoniana, espaço e tempo convertem-se em formas a priori do próprio sujeito, mas têm preservada sua natureza discreta e, portanto, mensurável. A crítica kantiana situa-se, assim, menos no nível da reformulação da realidade que no de uma crítica de seus princípios. Eis a base em que se erige a oposição entre a ontologia dogmática e a crítica; a segunda desbanca as pretensões produtivas, constitutivas da primeira. A produção epistêmica objetiva passa a ser privilégio das ciências modernas e a filosofia é reduzida ao papel acessório de purificação dos princípios de um conhecimento empírico que lhe é extrínseco. É nesse sentido que o modelo conceitual da atividade de determinação subjetiva é o de uma síntese, cuja forma é o juízo. É o juízo a forma de expressão científica por excelência. A forma judicativa é, desse

5 “O tempo, pois, não é inerente aos próprios objetos, mas unicamente ao sujeito que os intui.” (KANT, Crítica da razão pura, A 38/B 55)

6 Ibidem, A 372. 
modo, instituída como a forma da linguagem e do conhecimento, mas, também, da expressão da própria constituição da realidade cognoscível: "as condições dos objetos reais do conhecimento devem ser as mesmas que as condições do conhecimento"7. Com efeito, Kant nunca deixa de pressupor essa legitimidade dada dos postulados das ciências de seu tempo, mesmo que purificados pela crítica. Nesse sentido, seu propósito, ao menos na primeira Crítica, é duplo. De um lado, a restrição da legitimidade do conhecimento de objetos ao que possui substrato sensível; de outro, a garantia de que a experiência empírica seja, de direito, adequada aos critérios desse conhecimento.

Não se pode dissociar completamente as duas pretensões; o substrato sensível serve como critério do conhecimento legítimo de objetos sob a condição de que a própria experiência seja estruturada em função da atividade do entendimento no processo cognoscente. O significado kantiano desse processo desemboca justamente em uma relação entre o ser e o pensar, relação determinante entre o entendimento e a sensibilidade. Essa relação, no entanto, passa pelo esquematismo como liame entre as duas faculdades heterogêneas. Ora, sabemos que o tempo, tanto quanto o espaço, é reduzido por Kant à forma subjetiva em que aparece a realidade fenomênica. O que possibilitará, contudo, a caracterização kantiana do esquema transcendental como "um método de construir uma imagem em conformidade com um conceito" 8 é a ubiquidade fenomênica do tempo. Enquanto o espaço é designado como a forma dos objetos externos, percebidos como se "exteriores à mente", o tempo é a forma do sentido interno, da introspecção. Ele conforma os objetos em geral na medida em que, no processo de conhecimento, o sujeito figura introspectivamente todo objeto cognoscível. O esquema é, portanto, uma determinação propriamente temporal, de tal forma que ao tempo é atribuído o papel elementar de elo conceitual entre o sujeito transcendental, como realizador das sínteses originárias da realidade, e a própria realidade fenomênica condicionada. É desse ponto que parte a problemática de Deleuze: o condicionamento postulado por Kant não seria falso; ao contrário, seu grande mérito teria sido a descoberta do tempo como dimensão determinável. Seu erro, não obstante, teria sido ver na determinação de uma forma de possibilidade as condições

7 DELEUZE, Lógica do Sentido, p. 108 (Décima quinta série de paradoxos).

8 MORUJÃO, p.7o. In: Crítica da razão pura, op.cit. 
suficientes para uma explicação genética do mundo, rebatendo, assim, a cisão empírico/transcendental sobre uma determinação subjetiva.

Qual a relevância da forma do determinável como descoberta kantiana? Para Deleuze, é precisamente o elemento da descoberta, a visão de Kant de que algo prenunciava o lançamento da realidade no caos. Tratava-se do fato de que a descoberta do transcendental implicaria "uma falha ou uma rachadura no $E u$ ” através da qual o $E u$, separado pela forma do tempo, é duplicado em uma faceta empírica passiva e uma transcendental legisladora, cuja relação estabelece "a correlação do eu passivo e do EU rachado" ". Daí a fórmula de Rimbaud constantemente evocada por Deleuze para referir-se ao kantismo: "Eu é um outro" ${ }^{\circ}$, o que se desdobra, no contexto kantiano, no "paradoxo do sentido íntimo" ", o modelo narcísico da determinação como o de um Eu determinando a si próprio.

As consequências disto são extremas: minha existência indeterminada só pode ser determinada no tempo, como a existência de um fenômeno, de um sujeito fenomênico, passivo ou receptivo, aparecendo no tempo. Deste modo, a espontaneidade, da qual tenho consciência no Eu penso, não pode ser compreendida como o atributo de um ser substancial e espontâneo [como o Ego cartesiano], mas somente como a afecção de um eu passivo que sente seu próprio pensamento, sua própria inteligência, aquilo pelo qual ele diz EU, exercer-se nele e sobre ele, mas não por ele. (Diferença e repetição, p.132)

Haveria, portanto, de acordo com Deleuze, uma tensão violenta no próprio cerne da unidade do mundo empírico, baseada no espelhamento entre o conhecimento e o real. Ora, visto que esse espelhamento é condição mesma da ordem da experiência, a tensão na relação do $E u$ consigo mesmo se prolonga na ameaça dos fundamentos da própria realidade. Mesmo a unidade do divino é desestabilizada. Apesar da "ressureição prática" ${ }^{12}$ de Deus por Kant, em que ele serve, enquanto Ideia da razão, como um dos ideais da regularidade da experiência, o primeiro movimento de sua crítica é o de causar a "morte especulativa de Deus" ${ }^{13}$ pelo abandono da objetividade do divino.

\footnotetext{
9 Diferença e repetição, p.133.

10 DELEUZE, Crítica e clínica, p.42.

11 Diferença e repetição, p.133.

12 Diferença e repetição, p.134.

13 Ibidem, p.133.
} 
Sua representação passa a ser condicionada à renúncia de todo substrato sensível visto ser reduzida a um produto do uso puro da razão. Deus, como também a unidade do Eu e do próprio mundo, considerado como “conjunto dos fenômenos" ${ }^{14}$, é, assim, posto em questão pela filosofia crítica. A filosofia deleuziana pode ser mesmo compreendida como a exploração dos desdobramentos dessa tensão interna ao kantismo, exploração alicerçada, antes de tudo, na rejeição da solução kantiana, por sua vez fundada na postulação de "uma nova forma de identidade, a identidade sintética ativa [ou síntese transcendental da apercepção]”15. Para Deleuze, “é impossível manter a repartição kantiana, que consiste num esforço supremo para salvar o mundo da representação". Mais do que isso, “é numa avaliação totalmente distinta do eu passivo [ou empírico] que a iniciativa kantiana pode ser tomada, e que a forma do tempo mantém, ao mesmo tempo, o Deus morto e o Eu rachado" ${ }^{16}$.

Antes da elucidação da apropriação deleuziana da terceira síntese, é necessária a exposição do contexto ontológico em que ela é introduzida. A primeira coisa a ser notada aqui é que o modelo utilizado por Deleuze, em Diferença e repetição, para fundar sua ontologia, é ele mesmo de inspiração kantiana. Como em Kant, haverá a pretensão de identificar sínteses como modelos fundantes de uma realidade organizada, mas não será mais o juízo a encarnação desse condicionamento sintético. Em vez disso, sua abordagem será “tentar prover uma explicação alternativa da síntese do tempo que não se apoie nessa precisa divisão entre a atividade da consciência e a passividade do dado" ${ }^{17}$. Haverá, nesse sentido, a determinação de três sínteses como matrizes genética da realidade, sínteses ditas do tempo uma vez que a cada uma corresponde um regime temporal distinto.

\section{PRESENTE E PASSAdo Como sínteses ontológicas}

A primeira dessas sínteses circunscreve o âmbito mais próximo da experiência empírica kantiana, a temporalidade própria do presente. Há muitas nuances na forma como Deleuze descreve a primeira síntese, mas podemos destacar duas caracteri-

\footnotetext{
14 Crítica da razão pura, A 420/B 448.

15 Ibidem, p.134.

16 Idem.

17 SOMMERS-HALL, Henry, Deleuze's Difference and Repetition, pp.61-62. Tradução nossa.
} 
zações: primeiro, o caráter constitutivo do presente; segundo, sua pretensão fundacional, "originária"18 (o presente vivo é "verdadeiramente a fundação do tempo"19). Nessa síntese, em sua operação, há apenas presente, de modo que ele não constitui, no momento em que emerge, apenas uma dimensão de uma totalidade temporal mais abrangente. "A síntese constitui o tempo como presente vivo e constitui o passado e o futuro como dimensões deste presente" ${ }^{20}$ e não como momentos dele distintos. O que emerge no regime do presente é a realidade enquanto experiência que concebemos, de forma mais imediata, como sucessão de objetos espaço-temporalmente instanciados. Mesmo essa caracterização, no entanto, adequada ao kantismo, é pouco rigorosa para a definição deleuziana do presente. É verdade que o presente é compreendido como um domínio predominantemente identitário, baseado na recognição de objetos como forma primária de interação com as coisas, o que, é claro, é fundamental à praticidade instrumental da vida ${ }^{21}$. É preciso reconhecer para realizar tarefas cotidianas repetitivas, e em certo sentido fundamentais, o que justifica a tipificação da síntese do presente como um habitus, um hábito ${ }^{22}$. Mas a experiência própria do presente, à rigor, não se distingue tanto por sua objetividade quanto sua por sua duração. Para que haja tempo, não basta a sucessão de instantes de objetos independentes discretos que terminam tão logo têm seu início; tais instantes devem ser contraídos e unidos. Para que seja constitutivo, para que chegue a formar algo, o presente deve retirar dos instantes sucessivos nele instanciados uma diferença mínima, deve contraí-los em um "campo de temporalidade" 23 constituinte de uma fatia concreta da realidade.

18 Diferença e repetição, p.123.

19 Idem.

20 Ibidem, p.120.

21 Cf. o artigo O presente vivo em Bergson e Deleuze, in: Deleuze Hoje, em que Fernando Monegalha assinala a influência, na articulação deleuziana acerca da primeira síntese do tempo, das análises bergsonianas do presente vivo, mesmo que seja Hume o filósofo comumente associado à exposição do presente por Deleuze. Para Henri Bergson, o presente relaciona-se sobretudo à ação imediata: "Meu presente portanto é sensação e movimento ao mesmo tempo; e, já que meu presente forma um todo indiviso, esse movimento deve estar ligado a essa sensação, deve prolonga-la em ação. Donde concluo que meu presente consiste num sistema combinado de sensações e movimentos. Meu presente é, por essência, sensório-motor". (BERGSON, apud. Monegalha, p.239)

22 Diferença e repetição, pp.111-123.

23 SOMERS-HALL, Deleuze's Difference and Repetition, p.72. Tradução nossa. 
Objetos são, nesse sentido, componentes de ritmos que os incluem como elementos, ou eles mesmos durações de elementos ou instantes que os constituem. O modo próprio da potência constitutiva do presente é, portanto, o da contração ${ }^{24}$. O mundo, em vez de instanciado em sucessão temporal global de uma mesma dimensão que abrange todos os seres, é a totalidade dos ritmos qualitativos coexistentes, cada um dotado de uma duração específica. Como bem aponta Henry Somers-Hall, “podemos ver, por exemplo, que o coração se contrai, não no sentido do movimento que ele de fato realiza, mas na medida em que ele organiza uma sucessão essencialmente indiferente em uma série de momentos de uma duração particular (sua batida)." 25 Vemos, nesse sentido, que a síntese do presente é passiva, não ativa como no caso kantiano; o sujeito não realiza sínteses, ele é formado nesse processo, é um resíduo da produtividade temporal.

Esse caráter constitutivo e, portanto, originário do presente deleuziano não impede que ele seja fundado sobre um aparente paradoxo: “constituir o tempo, mas passar neste tempo constituído” ${ }^{26}$. Mesmo que não se reduzam à sucessão de elementos independentes, os ritmos instaurados pelo presente, imbricados uns nos outros, ainda detêm durações limitadas, as quais, ao se esgotarem, devem dar lugar a outras. A síntese do presente é ainda intratemporal; engendra a temporalidade pois, ao fazer-se, esgota o tempo, tudo que é tempo torna-se nada mais que presente, mas trata-se ainda de um presente que passa. "Insistindo na finitude da contração, mostramos o efeito, mas não mostramos por que o presente passava, nem o que o impedia de ser co-extensivo ao tempo." ${ }^{27}$ Essa tensão entre a aparente redução do tempo ao presente e seu caráter irrevogavelmente passageiro torna necessária a indicação de uma instância mais fundamental que seja responsável pela passagem do tempo. Essa instância é o passado ou a segunda síntese do tempo.

24 Excluiremos dessa discussão o tema da contemplação, visto que tornaria ainda mais confusa a exposição dada a tendência de associar o conceito a uma potência de um sujeito já formado, quando, na verdade, o sujeito é um produto desse processo; ele contempla, mas também é, ele próprio, produto de contemplações que o precedem.

25 Op.cit., p.64. Tradução nossa.

26 Diferença e repetição, p.123.

27 Idem. 
O modelo conceitual decisivo para a articulação da segunda síntese é de matriz bergsoniana. O conceito deleuziano de passado parte, em primeiro lugar, na esteira de Henri Bergson, da rejeição do modelo representacional de passado, que concebe o passado à semelhança do presente, tal qual imagem localizada em um tempo anterior retrospectivamente reconstituído na mente do sujeito. Esse passado retrospectivo existe ele mesmo no presente, assim como o futuro, concebido como mera previsão de outro presente porvir. Nesse nível, o presente como tal inclui um passado e um futuro como suas dimensões na mesma forma do presente atual. Ambos passado e futuro, contudo, cristalizados no exercício ativo de retrospecção ou previsão, são concebidos como instantes formalmente indistintos do presente atual. O passado presentificado assim formado, passado representacional, é completamente distinto do passado de Bergson.

Como concepção alternativa, em grande medida tributária de noções bergsonianas, a segunda síntese concerne ao passado como existência em si mesma independente, um Todo repetido "em níveis diversos coexistentes" 28 , sendo o presente apenas "o grau mais contraído de uma totalidade inteira, que é em si como uma totalidade coexistente.” ${ }^{29}$. É um novo postulado ontológico, que Bergson concebe sob a forma de um cone, de sua ponta ao círculo de sua base indo de seu nível menos contraído ao mais contraído, cada um uma síntese dele próprio. Esse cone seria índice de imanência entre o presente e o passado, em que o primeiro designaria a forma mais contraída do último, contração esta formada ao contrair um dos níveis do passado, o qual, por sua vez, concentra todo o resto de forma mais ou menos contraída. Trata-se de um passado, portanto, que nunca foi presente, que é, em seu ser, somente passado, cuja forma “pura” suporta um grau máximo de distensão, em oposição ao grau máximo de contração no presente. Sendo o presente um conjunto de instantes, tem sua razão de ser no passado como um fundamento. "É pelo elemento puro do passado, como passado em geral, como passado a priori, que tal antigo presente é reprodutível e que o atual presente se reflete" ${ }^{\circ}$, i.e., que o passado se constitui como retrospecção ativa no presente. O passado como segunda síntese, no entanto, é justamente aquele que

28 Ibidem, p.129

29 Ibidem, p.128.

30 Ibidem, p.125. 
não é memória concebida como retrospecção ou previsão, e que sintetiza, também de modo passivo, vários níveis que o próprio presente retoma em seu funcionamento.

Ambos presente e passado já fornecem, assim, uma descrição, digamos, suficiente da realidade. O problema é que, em certo sentido, introduzir o passado como fundamento a priori, pura e simplesmente, parece retomar o kantismo em moldes bergsonianos, no sentido de que, em vez de um condicionamento transcendental, haveria um passado em si, mais fundamental que o presente, e a relação entre este último e o passado esgotaria explicativamente o real. Para Deleuze, deve haver uma terceira síntese que destitui o passado de seu lugar de fundamento; seu em-si não deve ser tomado como base última de que deriva o tempo, mas como “uma espécie de 'efeito', como um efeito ótico" ${ }^{31}$ gerado pelo movimento de uma instância mais profunda, uma instância diferencial.

\section{A TERCEIRA SíNTESE do TEMPO E A FORMA IMUTÁVEL DA DIFERENCIAÇÃo}

Finalmente, é na terceira síntese do tempo que o tema kantiano da forma pura e vazia do tempo será retomado por Deleuze. Enquanto as duas primeiras sínteses são apresentadas como geradoras de uma certa estruturação da realidade, a terceira será descrita somente em um segundo momento em um contexto ontológico, sendo posta, em primeiro lugar, em sentido ético. Ela é caracterizada como um momento de criatividade absoluta que produz o futuro, dimensão que é desencadeada no terceiro de três momentos conceituais em que a própria síntese é fragmentada. Como condições desse terceiro momento, os dois iniciais dirão respeito à capacidade de ação de um personagem em específico, exemplificado pelas figuras de Hamlet e de Édipo. A condição da própria passagem do tempo, compreendido como futuro ou criação, é, portanto, a agência, manifesta em uma ação formidável que põe em curso a terceira síntese através da aplicação de um poder destrutivo que descobre a forma vazia.

Deleuze enfatiza que a forma é concebida a partir de uma "reversão kantiana" 32 do tempo em que ele deixa de ser compreendido como simples medida do movimento, o que o caracterizava na cosmologia antiga. Como o Demiurgo de Platão, que vincula, acreditava Timeu, o caráter mensurável do tempo à ordem do movimento dos plane-

31 Ibidem, p.134.

32 DELEUZE, Crítica e clínica, p.41, 
$\operatorname{tas}^{33}$, a ontologia antiga define o tempo como "imagem movente da eternidade" 34 , o "número do movimento" 35 , dizem Platão e Aristóteles. Ele próprio não é nada sem o que nele se move. A forma do tempo, concebida por Kant, inverte a relação: é o movimento que passa a ser subordinado, condicionado pelo tempo. Ele se torna "ordinal, ordem do tempo vazio. [...] Tudo o que se move e muda está no tempo, mas o tempo ele mesmo não muda, não se move e tampouco é eterno. Ele é a forma de tudo o que muda e se move, mas é uma forma imutável e que não muda" ${ }^{36}$.

Ultrapassando o kantismo, a terceira síntese emerge justamente a partir da constatação de que a forma atesta uma cesura, não a determinação de um horizonte de possibilidades, no cerne da constituição temporal. A cesura, termo de Friedrich Hölderlin, é designada pelo autor como a essência do trágico, cuja função, manifesta nas tragédias de Sófocles, é uma "interrupção anti-rítmica" 37 através da qual o decurso da tragédia é dividido por um acontecimento em particular (a chegada de Tirésias, no caso de Édipo Rei). Jean Beaufret verá na figura hölderliniana da cesura o retraimento do divino, a ausência permanente deixada pela figura decaída de Deus na modernidade, resultado de um "afrontamento do divino e do humano" que resulta no "afastamento categórico" divino ${ }^{38}$. Para Beaufret, a noção de afastamento categórico teria sido resultado de influência kantiana sobre Hölderlin, representativa do novo significado moderno da lei manifesta no imperativo categórico e símbolo da condenação kantiana da moral teológica. "Eliminação da moral teológica em prol de uma teologia moral, ela não é mais visão de Deus, mas desde já retraimento do divino. A lei é o documento mais próprio desse retraimento. Se Deus é presença, é por exclusão de toda 'representação intuitiva"” 39 . A forma do tempo será condição da inscrição secular da lei na própria ordem da experiência; Deus é o tempo e o tempo "é reduzido ele próprio àquilo que é nele pura 'condição', isto é, à sua forma pura e vazia” ${ }^{\circ}$. Com efeito, afirma Deleuze

33 SOMERS-HALL, op.cit., pp.73-74.

34 VOSS, Deleuze's Third Synthesis of Time, p. 195. Tradução nossa.

35 Idem.

36 Crítica e clínica, pp.41-42.

37 HÖLDERLIN, Observações sobre Édipo, p.69.

38 BEAUFRET, Hölderlin e Sófocles, p.19.

39 BEAUFRET, op.cit., p.21. Grifos do autor.

40 Ibidem, p.31. 
que "a saída do kantismo não está em Fichte ou em Hegel, mas somente em Hölderlin, que descobre o vazio do tempo puro e, nesse vazio, o afastamento contínuo do divino, a rachadura prolongada do $\mathrm{Eu}[\mathrm{J} e]$ e a paixão constitutiva do Eu [moi]" ${ }^{41}$. É em uma sistematização propriamente ontológica que Deleuze vai reativar o tema da cesura de Hölderlin, cesura que divide conceitualmente a forma vazia do tempo em três momentos.

O primeiro desses momentos delimita uma "ordem formal vazia” ${ }^{42}$ que separa o tempo em três polos: o passado, o presente e o futuro. Essas determinações não são, como no esquema kantiano, momentos de um tempo homogeneamente cronológico, mas também não correspondem ao presente e ao passado da primeira e da segunda síntese de Deleuze. Elas são lugares formais a serem ainda preenchidos; determinados, portanto, de maneira meramente formal. São coordenadas da própria forma vazia. Sua única positividade concerne à “distribuição puramente formal do desigual em função de uma cesura" 43 . O passado e o futuro se tornam fatias assimétricas unidas por sua própria divisão. A essa ordem temporal se seguirá uma segunda característica da forma vazia, um conjunto do tempo, que atribui a cada polo da ordem uma função específica em cada contexto particular em que o tempo se desenrola.

a ideia de um conjunto do tempo corresponde ao seguinte: que a cesura, seja ela qual for, deve ser determinada na imagem de uma ação, de um acontecimento único e formidável, adequado ao tempo inteiro. Esta própria imagem existe sob uma forma dilacerada, em duas porções desiguais; todavia ela reúne assim o conjunto do tempo. Ela deve ser tida como um símbolo em função das partes desiguais que subsume e reúne, mas reúne como desiguais. Tal símbolo, adequado ao conjunto do tempo, se exprime de muitas maneiras: tirar o tempo dos eixos, despedaçar o sol, precipitar-se no vulcão, matar Deus ou o pai. Esta imagem simbólica constitui o conjunto do tempo, na medida em que ela reúne a cesura, o antes e o depois. ${ }^{44}$

Como em Hölderlin e sua cesura trazida pelo herói trágico, o problema do conjunto do tempo será o de união formal de cada momento da ordem temporal mediante sua

\footnotetext{
41 Diferença e repetição, p.134.

42 Ibidem, p.136.

43 Idem.

44 Ibidem, p.137
} 
conformação ao conjunto, por sua vez reunido sob a figura da cesura ou "ação formidável" que une as duas fatias assimétricas do tempo. De que se segue a terceira e última característica da forma elencada por Deleuze: uma série temporal que atribui, em função do conjunto ou imagem simbólica, papeis específicos a cada um dos momentos formais do tempo. O passado, em primeiro lugar, como "primeira parte do símbolo”, passa a ser o momento em que o agente individuado se reconhece como pequeno demais para a realização de uma determinada ação. É sinônimo, portanto, de impotência. "Édipo já praticou a ação, Hamlet ainda não; mas, de qualquer modo, eles vivem a primeira parte do símbolo no passado, vivem eles próprios e são rejeitados no passado enquanto sentem a imagem da ação como grande demais para eles" ${ }^{45}$. O presente, por sua vez, aparece como o momento da própria cesura, o "devir igual à ação”, em que o agente se torna efetivamente capaz de agir. O futuro, por fim, é o momento da criação absoluta, acontecimento cuja “coerência exclui a do eu, voltando-se contra o eu que se lhe tornou igual, projetando-o em mil pedaços [...]: aquilo a que o eu é igualado é o desigual em si” ${ }^{46}$.

Voltando às duas primeiras sínteses do tempo, lembramos que o presente é constitutivo e, nesse sentido, o conteúdo do tempo, de que o passado é o fundamento. São essas determinações funcionais que vão torná-los ocupantes dos polos formais na pura ordem temporal. É preciso, no entanto, discernir dois sentidos da exposição de Deleuze a respeito das três sínteses. Em um sentido, o presente e o passado funcionam como mecanismos constituintes de uma mesma realidade coerente, circunscrita pela forma do tempo; em outro, presente e passado são meros instrumentos de um terceiro tempo que rompe a estrutura ontológica de que aqueles faziam parte, rompimento este que sua parte formal também implica. É este o sentido do futuro ou terceira síntese do tempo. A ação do futuro "subordina as duas outras[sínteses] e as destitui de sua autonomia” ${ }^{47}$, pois destrói o próprio contexto estrutural em que elas estavam postas de início. Nesse momento, “o presente é apenas um ator, um autor, um agente destinado a apagar-se; e o passado é apenas a condição operando por insuficiência" 48 . Na medida em que o presente, sendo a fundação do tempo, é o único regime tempo-

\footnotetext{
45 Idem.

46 Idem.

47 Ibidem, p.141.

48 Ibidem, p.140.
} 
ral a ter consistência material, a terceira síntese precisa usá-lo para introduzir-se na organização do tempo e desfazê-la, o que torna o presente um agente, um veículo da terceira síntese; o passado, por sua vez, torna-se condição, pois é ele que fornece a matéria imanente de que faz uso o presente para constituir-se. A terceira síntese é, assim, como índice dinâmico de ligação entre o presente e o passado, cujo resíduo, o novo, tem sua criação condicionada à dissolução do plano em que operavam as duas sínteses, instaurando "uma via de acesso para a heterogênese complexual, [...], intolerável foco de criacionismo ontológico" 49 que dissolve o espaço-tempo.

A cesura ou fissura da forma do tempo designa, assim, um momento destrutivo, que, realizado no presente por intermédio de uma “ação formidável”, englobante do conjunto do tempo, introduz o eterno retorno como imagem do futuro. $\mathrm{Na}$ exposição deleuziana, apropriada de Nietzsche e influenciada pela leitura de Pierre Klossowski, o eterno retorno é a ascensão de um fundo ou sem-fundo diferencial que, em seu processo de emergência, "implica a destruição de todas as formas que impedem seu funcionamento, categorias da representação encarnadas no caráter prévio do Mesmo, do Uno, do Idêntico e do igual" ${ }^{\circ}$; em suma, de identidades em geral. O modelo da ação da diferença é, nesse sentido, o da destruição diferencial de identidades, em que o “retorno" é compreendido como uma potência ontológica seletiva que faz retornar somente o que é novo ou singular ${ }^{51}$.

Para concebermos melhor esse movimento de "emergência" destrutiva da diferença, cabe a remissão ao panorama conceitual em que é introduzido, em Diferença e repetiçã $0^{52}$. Sabe-se que o problema principal do livro é definido como a elaboração

49 GUATTARI, Caosmose, p.97.

50 Diferença e repetição, p.183.

51 Sobre a terceira síntese, Joe Hughes observa que "é como se houvessem três sínteses na terceira síntese somente. A primeira é uma síntese que falha em relação ao objeto (ordem do tempo). A segunda é uma síntese que falha em relação ao sujeito (série do tempo). A terceira, a única síntese bem-sucedida, é aquela do eterno retorno, ou a síntese ideal da diferença." (HUGHES, Deleuze's 'Difference and repetition', a reader's guide, p.163, tradução nossa) É muito interessante essa ideia da terceira síntese como uma síntese que "falha". É, com efeito, nesse sentido que a terceira síntese é quase o simétrico oposto da síntese transcendental kantiana; esta estabelece a unidade necessária do mundo, aquela falha ao tentar fazê-lo e funda necessariamente a organização sobre um sem-fundo.

52 Cumpre destacar que essa formulação designa uma articulação conceitual repetida muitas vezes no trabalho de Deleuze: a de um movimento genético que engendra o absolutamente novo após 
de um conceito de diferença capaz de romper sua subordinação à identidade de que foi dotada na tradição filosófica. O texto define a diferença de várias maneiras. Em um sentido, ela é a Diferença transcendental “entre a determinação e o que ela determina" 53; em outro, é o "númeno mais próximo do fenômeno" 54; depois, é ainda igualada à noção de intensidade, quando refere-se à geração da realidade sensível55. Não obstante, a diferença jamais é tomada como um ente entre outros, seja lá de que forma se o conceba; mesmo o conceito de diferença não equivale à própria diferença. Quando Deleuze sugere a possibilidade de “experimentação” real, concreta da diferença, exemplifica os casos de "experiências farmacodinâmicas, ou experiências físicas como as da vertigem", capazes de revelar "esta intensidade em si no momento original em que ela não é mais qualificada nem extensa [i.e., que não se encontra cristalizada no presente]" ${ }^{56}$. Conceitualmente, pode-se dizer que essas articulações exprimem a tentativa de se remover do domínio psíquico essa espécie de perspectiva diferencial caótica que, exemplificada pelas experiências psicotrópicas e de vertigem, é caracterizada pela dissolução das determinações normalmente em vigor na experiência comum. O caos assim instaurado não seria um caos mental, mas a dissolução objetiva e muito breve do próprio chão constituinte da estabilidade do real que enreda o sujeito como um de seus componentes.

A essa destruição corresponde um processo de constituição, uma atualização, dirá Deleuze, de qualidades e partes extensas, em que serão reconstituídas as esferas do presente e do passado. O que possibilitará a caracterização do futuro como produtor do novo é a matriz necessariamente diferencial desse processo de constituição, que difere em natureza do horizonte identitário e presentificado por ele determinado. “A atualização, a diferenciação, neste sentido, é sempre uma verdadeira criação" 57 , de tal modo que, quando o presente e o passado são reconstituídos, sua estrutura é com-

a destruição de um regime identitário de realidade que impede esse processo criativo. A mesma noção aparece (evidentemente, em correspondência a problemas muitos distintos) na figura da desterritorialização, do Anti-Édipo e de Mil Platôs; da precipitação na fissura ou nas profundidades, na Lógica do Sentido; e na apropriação das forças do caos, em O que é filosofia?.

53 Diferença e repetição, p.132.

54 Ibidem, p. 313.

55 Ibidem, p. 314.

56 Ibidem, p. 334 .

57 Ibidem, p. 299. 
pletamente renovada. O futuro é, assim, como o terceiro e destrutivo tempo de uma série a ser destruída, mas o primeiro de uma outra que ele engendra diferencialmente. Retomando o tema do futuro e das duas primeiras sínteses, temos agora melhores condições de explanar sua relação com a diferença ascendente na forma do tempo. O presente, como já exposto, retira sua concretude do passado, que aparece como seu fundamento. É função do presente organizar esse passado segundo formas mais ou menos determinadas, discretas e sucessivas. Sabemos agora, no entanto, que o passado "se ultrapassa em direção a uma terceira síntese, que denuncia a ilusão do em-si como ainda sendo um correlato da representação" ${ }^{8}$; se ultrapassa justamente no sentido de que o movimento pelo qual o passado e o presente são gerados é a própria terceira síntese. O passado perde seu caráter em si pois deixa de ser fixo: ele também é diferenciado. Uma vez que ambos passado e futuro são correlacionados pela diferença na terceira síntese, esta se torna a própria figura do futuro, cujo modelo é a destruição e reconstituição criativa do presente, fundação do tempo. O futuro é a novidade pois o prosseguimento real do tempo, o chamado verdadeiro movimento, ocorre mediante a reestruturação necessária e diferencial do campo em que o real se desenrola, o tempo como potência auto-sintética produtora de si mesma.

O esquema interpretativo que queremos propor pode ser resumido nos seguintes termos: Deleuze mantém o formalismo que determina a experiência empírica em chave kantiana, o caráter de direito a priori de sua estrutura, mas o modifica a partir da afirmação de que a atribuição da potência organizadora da forma, da maneira que Kant a concebe, é ilegítima, pois suprime o próprio tempo enquanto emergência do absolutamente novo ao soldar o sujeito empírico e o sujeito transcendental (O Eu e seu Outro) por uma síntese que projeta sobre a forma pura do tempo seu preenchimento parcial dado. Preenchimento determinado por categorias a priori. Por mais que a forma, em Kant, seja um dos momentos da determinação dos dados sensíveis pelo sujeito, ela ganha sua estrutura empírica apenas a partir da modulação ativa do entendimento. A forma do tempo não é ainda a determinação responsável pela unificação sintética da experiência empírica, mas a forma do determinável, que o entendimento, como faculdade legisladora, organiza em uma síntese transcendental. O sujeito transcendental, face ativa do sujeito, deve determinar sua contraparte empírica e 
passiva, o que, para Deleuze, atesta a existência de uma "rachadura do Eu" ou "forma vazia e pura", que divide o Eu em duas metades assimétricas, o que denuncia, por um lado, a irredutibilidade do tempo a uma forma de possibilidade subjetiva e, por outro lado, o caráter não originário do Eu, em realidade constituído por sínteses passivas. A síntese ou "identidade sintética ativa" teria sido a tentativa kantiana de suprimir a lacuna deixada pela divisão entre o Eu ativo transcendental e o eu passivo empírico, fundando uma relação de analogia em que a estrutura transcendental serve de molde aos dados sensíveis inicialmente difusos. É como se Kant preenchesse parcialmente a forma, incluísse em seu escopo um enxerto identitário permanente, englobante de tudo sobre o que ela se aplica. O conhecimento, por sua vez, fecha o círculo do desejo de regularidade kantiano por baixo da parafernalha conceitual da primeira Crítica.

Em Deleuze, ao contrário, a forma do tempo, em vez de reduzir-se à impressão de uma estrutura causal e identitária ao real, ganha uma propriedade diferencial, a partir da qual a realidade comportará, de fato, a identidade, mas esta irá, de direito, oscilar entre sua sustentação e seu eventual desfazimento. Em vez de funcionar como condição intermediária entre conceito e intuição, a forma, portanto, funciona como índice de tração da diferença sobre o presente e do presente sobre a diferença, tração manifesta tanto pela emergência do presente quanto por "movimentos forçados”, encenações violentas do eterno retorno. É por isso que a forma vazia precisa ser postulada por Deleuze; ela formaliza a priori ${ }^{59}$ a própria relação de diferenciação, o que faz com que o movimento diferencial seja genético, no sentido de manter-se como intermediário entre a estabilidade e a diferença em vez de dissolver-se no caos irrestrito. Nesse sentido, a forma, de um lado, é vazia, pois não se submete à calcificação de suas estruturas à maneira kantiana, o que permite que o engendramento da realidade se dê de forma inteiramente contingente dadas as possibilidades constitutivas infinitas em sua matriz diferencial. Por outro lado, a forma não é sinônimo de indeterminação completa, pois, graças à sua estrutura formalmente tripartite, garante que a cisão seja sinônimo de uma ruptura entre um passado deficiente e a criação, mas não de indeterminação tout court. Assim, a relação entre o presente e a diferença é erguida em um pano de fundo imanente, de tal modo que o primeiro não enclausure a diferença de vez e que a última não lance o mundo no caos permanente. O presente é, portan-

59 Sobre o necessário formalismo da terceira síntese, Lapoujade afirma que "o tempo da terceira síntese é um tempo lógico, puramente lógico, para além de toda duração”. (Op.cit., p. 82) 
to, formal; mas também o é a diferença: o formalismo incide sobre sua relação e os define, a priori, como inseparáveis um do outro; "identidade interna do mundo e do caos" ${ }^{60}$, unidade entre crítica e ontologia, instauração de uma ética constitutiva ${ }^{61} \mathrm{ou}$, como diz Guattari, de um paradigma ético-estético. É por isso que o eterno retorno descobre uma forma pura e vazia: quando as identidades do presente são aniquiladas, a forma, assim esvaziada, deve ser novamente preenchida. Uma vez que esse preenchimento não se dá senão sob a agregação de um movimento diferencial, tem necessariamente o caráter de uma criação; portanto, de uma contingência absoluta.

A diferença pode ser compreendida como uma versão diferencial do elã vital bergsoniano ou do conatus spinozista, no sentido de um movimento que, ao mesmo tempo em que é imanente ao que é identitário, bem formado, é a razão irredutível da destruição de entidades já formadas. Sua função é a alteração das entidades a ele imanentes, até o ponto em que suas formas não suportam mais a violência de suas alterações e se desfazem, dando origem a outras. A diferença se torna um vetor de diferenciação cuja faceta destrutiva é sempre seguida da atualização de novas identidades: "não é menos capaz de dissolver e destruir os indivíduos quanto de constituí-los temporariamente" ${ }^{2}$.

Essa tendência duplamente genética e destrutiva fica evidente quando Deleuze chama, à propriedade geneticamente identitária da diferença, uma ilusão transcendental necessária, em que "a identidade e a semelhança são [...] efeitos de funcionamento [...][do movimento diferencial] que projetaria necessariamente sobre si mesmo a ilusão de uma identidade fictícia e [...] a ilusão de uma semelhança retrospectiva" ${ }^{63}$. A contingência está no liame produtivo entre a diferença e o sistema de identidade, na forma do que é engendrado por essa relação. O sistema aparece, assim, como um resíduo da diferença, um efeito secundário de movimentos aberrantes que não o constituem senão por acidente. É este o paradoxo fundamental de uma ontologia criativa ou produtiva: a tentativa de aproximação máxima da diferença, desse fundo

60 Ibidem, p.411.

61 Na mesma linha, diz Lapoujade que "se o ser (como novo fundamento) tem como máquina abstrata o eterno retorno (como novo princípio transcendental), então a ontologia se torna imediatamente ética, se confunde com uma ética." (Op.cit., p.91, grifo do autor)

62 Diferença e repetição, p.70.

63 Ibidem, p.175. 
sem-fundo, sem a perda das condições da determinação, de um mínimo de estabilidade ontológica. A criatividade, em Kant radicada e domesticada na potência condicional do sujeito transcendental, limitada à repetição da materialidade descontínua da empiria, transfigura-se em uma forma da diferenciação ou do futuro, da criação absoluta, cuja eventualidade desfaz as estruturas calcificadas do sujeito e da identidade, as quais, em Kant, designam a ordenação mediada pela forma do tempo. A forma vazia assegura, assim, determinação suficiente para que haja identidade e indeterminação suficiente para que essa identidade seja expressão do caos genético por trás das estruturas que ele origina ${ }^{64}$. Eis as condições de uma desumanização da potência criativa ou ativa, uma imanentização do mundo e da agência. A contingência se torna necessária pela criação de um modelo formal, por um lado, largo o suficiente para comportá-la e, por outro, estrito ao ponto de elevá-la ao estatuto de necessidade. A forma fecha seu ciclo sobre a aniquilação do que ela funda, pois seu movimento é o de um erro, de uma ficção, sem que isso a torne menos real. A condição da formação é a necessidade da dissolução do que foi formado.

Se essas indicações sugerem uma nova concepção de sistema, trata-se de um sistema cuja organização tem por propósito a expressão do próprio caos ou diferença. Sua singularidade funda-se no reconhecimento interno de sua própria finitude: é atravessado pela expectativa de sua própria superação, pela visualização de seu próprio limite. Evidentemente, é difícil não ver na filosofia de Deleuze uma tentativa de explicação total da realidade, o que é sugerido por alguns de seus exemplos mais concretos, como o desenvolvimento embrionário e a relação entre a vespa e a orquídea. Não obstante, o movimento verdadeiro, o movimento da diferença é definido pela capacidade de reconfigurar completamente qualquer aspecto da realidade; definição que culmina na tão repetida máxima de que a filosofia é criação de conceitos. Parece haver, assim, uma tensão entre a tentativa de explicação exaustiva do real e a sugestão da inevitabilidade da superação do próprio sistema a partir do qual essa explicação

64 "Oscila-se assim entre, por um lado, um mundo finito em velocidades desaceleradas, em que um limite se esboça sempre por trás de um limite, uma coação por detrás de uma coação, um sistema de coordenada por detrás de outro sistema de coordenada, sem que se chegue jamais à tangente última de um ser-matéria que escapa por toda parte e, por outro lado, Universos de velocidade infinita em que o ser não se recusa mais, em que ele se dá em suas diferenças intrínsecas, em suas qualidades heterogenéticas. [...] Cruzamento do finito e do infinito, nesse ponto de negociação entre a complexidade e o caos". (GUATTARI, Caosmose, p.126.) 
é produzida, melhor manifesta no tema da criação. Já que a filosofia deve criar conceitos, há espaço permanente para o engendramento de novos sistemas. Como diz Deleuze, a "forma do tempo só existe para a revelação do informal no eterno retorno" ${ }^{65}$. A imagem de pensamento assim fundada é paradoxal pois explica a si própria como momento da diferença; considera, em seu próprio desenvolvimento, no que ela expressa sistematicamente, sua própria diferenciação. A criatividade é, portanto, seu único postulado insuperável. Todos os seus conceitos têm sua razão sobretudo na "identidade interna entre o caos e o cosmos", nas condições mediante as quais a organização conceitual, em virtude de sua configuração, é capaz de fazer o sem-fundo falar. A filosofia transfigura-se, assim, em uma ação produtiva. Não como a apologia doutrinária de um quadro conceitual único, tampouco o relativismo irrestrito que prolifera verdades independente; mas a verdade da própria produção de realidades. Verdade da relatividade em vez de relatividade da verdade.

\section{BIBLIOGRAFIA}

DELEUZE, Gilles. Crítica e clínica. 2a edição. Tradução de Peter Pál Pelbart. São Paulo: Editora 34, 2013.

Diferença e repetição. 2a edição. Tradução de Roberto Machado e Luiz B. Orlandi. Rio de Janeiro: Graal, 2006.

Lógica do sentido. 5 a edição. Tradução de Luiz Roberto Salinas Fortes. São Paulo: Perspectiva, 2015.

FORNAZARI, Sandro Kobol. (Coord.); AZEVEDO, A.B. et al. (Orgs). Deleuze Hoje. São Paulo: Editora Fap-Unifesp, 2014.

GUATTARI, Félix. Caosmose. 2a edição. Tradução de Ana Lúcia de Oliveira e Lúcia Cláudia Leão. São Paulo: Editora 34, 2012.

HARDT, Michael. Gilles Deleuze: An Apprenticeship in Philosophy. Minneapolis: University of Minnesota Press, 2002.

65 Diferença e repetição, p. 139. 
HUGHES, Joe. Deleuze's 'Difference and Repetition': A Reader's Guide. London: Continuum, 2009.

HÖLDERLIN, Friedrich.; BEAUFRET, Jean. Observações sobre Édipo e Observações sobre Antígona. Rio de Janeiro: ZAHAR, 2008.

KANT, Immanuel. Crítica da razão pura. 8a edição. Lisboa: Fundação Calouste Gulbenkian, 2013.

LAPOUJADE, David. Deleuze, os movimentos aberrantes. Tradução de Laymert Garcia dos Santos. São Paulo: n-1 edições, 2015.

SOMERS-HALL, Henry. Deleuze's Difference and Repetition. Edinburgh: Edinburgh University Press, 2013 .

VOSS, Daniela. Deleuze's Third Synthesis of Time. Deleuze Studies. Número 2, volume 7,2013 . 